\title{
Microbial-Driven Stabilisation of Archaeological Iron Artefacts
}

\author{
Sarah James ${ }^{1}$ (D) and Edith Joseph $1,2, *$ (D) \\ 1 Laboratory of Technologies for Heritage Materials (LATHEMA), University of Neuchâtel, \\ 2000 Neuchâtel, Switzerland; sarah.james@unine.ch \\ 2 Haute école- Arc (HE-Arc), 2000 Neuchâtel, Switzerland \\ * Correspondence: edith.joseph@unine.ch
}

Citation: James, S.; Joseph, E. Microbial-Driven Stabilisation of Archaeological Iron Artefacts. Corros. Mater. Degrad. 2021, 2, 274-292. https://doi.org/10.3390/cmd2020015

\section{Academic Editors}

Panayota Vassiliou, Emma Angelini, Sabrina Grassini and Judit Telegdi

Received: 30 December 2020

Accepted: 24 May 2021

Published: 4 June 2021

Publisher's Note: MDPI stays neutral with regard to jurisdictional claims in published maps and institutional affiliations.

Copyright: (c) 2021 by the authors. Licensee MDPI, Basel, Switzerland. This article is an open access article distributed under the terms and conditions of the Creative Commons Attribution (CC BY) license (https:/ / creativecommons.org/licenses/by/ $4.0 /)$.

\begin{abstract}
The instability of iron artefacts is rooted in salt contamination during burial and damages associated with exposure to alternative oxygen levels and high relative humidity once excavated. While a combination of chemical and mechanical treatments is utilised to remove the harmful ions (chlorides, sulphur species) and excess bulky corrosion products, these methods can be hazardous for conservation staff's health, have limited success, or require extensive treatment times. Bio-based treatments provide a potentially greener alternative for removing damaging corrosion and creating biogenic mineral passivation layers, thus remediating concerns over costs, duration, and health and safety. Pseudomonas putida mt-2 (KT2440) is capable of utilising iron under certain conditions and for phosphating mild steel; however, applications have not been made in the cultural heritage sector. To address the potential of using bacteria for conservation purposes, Pseudomonas was assessed for both the bioremediation of salt contaminates and the production of a passivation layer suitable for iron artefacts, with specific conservation concerns in mind. Key factors for optimisation include the role of agitation, chloride content, and oxygen content on bacterial growth and biomineralisation. The initial results indicate a growth preference, not reliance, for $\mathrm{NaCl}$ and agitation with partial success of bioconversion of a mineral source.
\end{abstract}

Keywords: iron; microorganisms; biogenic minerals; iron reduction; cultural heritage; green conservation

\section{Introduction}

The premise for bio-based treatment of corroded or contaminated metal is founded in the utilisation of microorganisms or microbial-produced compounds (i.e., enzymes, siderophores) to consume, convert, or stabilise metallic surfaces without the need for harsh chemicals. Iron artefacts are exceedingly common in both archaeological and historical collections. Over the past century, several different treatments have been developed, each with advantages and limitations. The primary issue with iron artefacts is their instability due to voluminous corrosion products and salt contamination.

The global trend for ethical environmental practices has led conservation science to address the environmental and health risks associated with prominent object treatments, while conservation professionals continuously search for treatment plans that are also cost-effective, adaptable, and timely [1]. After consultation with various conservation laboratories in Switzerland, a few key goals were confirmed: 'to treat active corrosion and create passivation layer', 'to have a field protocol to prevent post-excavation rapid corrosion' and 'to soften extreme concretions for removal' [2].

The primary issue with iron artefacts is their instability due to voluminous corrosion products and salt contamination during burial. Anions, such as chlorides present in the object's burial environment or atmosphere (marine sites), create an electrolytic solution that reacts with iron when in the presence of moisture and oxygen. The chloride content in archaeological finds is linked to akaganeite $(\beta-\mathrm{FeOOH})$, as well as other products such as hydrochloric acid $(\mathrm{HCl})$ and ferrous hydroxychloride $\left(\beta-\mathrm{Fe}_{2}(\mathrm{OH})_{3} \mathrm{Cl}\right)$ [3-5]. Recent studies 
suggest $\mathrm{FeO} 0.833(\mathrm{OH}) 1.167 \mathrm{Cl} 0.167$ as a more representative chemical formula for its crystal structure [6]. Chloride concentration in $\beta$-FeOOH and archaeological ironworks can range from 1.3 to $17.0 \%(w / w)$ [7-9]. However, the literature suggests chloride readings below $200 \mathrm{ppm}$, or $0.02 \%$, to be within a safe range [10-13].

The fluctuation of atmospheric parameters from burial to excavation exacerbates this process and can lead to a fracturing of the object's surface, bulky corrosion products, weeping, and more [14]. Akaganeite has been cited for a long time as a primary indicator of corrosion rather than the cause [15]. However, this epithet does not account for the mineral's voluminous nature nor the chloride content necessary for its formation. In actuality, structural damage also occurs as shifts in moisture levels cause bulking and a collapse of the corrosion layer-leading to spalling or cracking $[16,17]$. $\beta$-FeOOH forms when chloride content is sufficient to maintain the mineral structure, with chloride ions trapped within the mineral tunnel network. The presence of these free chloride ions presents a risk of reinitiating the mechanisms of corrosion. 'Weeping' or 'sweating' active corrosion appears as brown, yellow, or orange acidic droplets that form on objects at high relative humidity $(\mathrm{RH})$ in the presence of chlorinated salts [17]. During an oxygen-free burial environment, microbial processes (SRB) often produce hydrogen sulphide $\left(\mathrm{H}_{2} \mathrm{~S}\right)$, which degrades archaeological iron artefacts and leads to the formation of iron sulphides. These compounds, primarily mackinawite $(\mathrm{FeS})$, greigite $\left(\mathrm{Fe}_{3} \mathrm{~S}_{4}\right)$, or pyrite $\left(\mathrm{FeS}_{2}\right)$, react in the presence of oxygen and moisture to form sulfuric acid and iron oxyhydroxides, such as goethite $[18,19]$.

Conservation approaches are either interventive or passive. Passive approaches function by limiting parameters that would perpetuate the degradation process, such as oxygen or moisture levels (e.g., desiccation). In contrast, chemical treatments function by removing the harmful ions (chlorides $\mathrm{Cl}^{-}$, sulphur $\mathrm{S}^{2-}$ species); and mechanical methods remove excess bulky corrosion products. Conservation professionals widely use interventive and passive approaches, such as desalination and desiccation via silica gel, yet evidence suggests desiccation is not sufficient for all deterioration types [20,21].

Additionally, chemical treatments range in success and can be harsh on the objects and hazardous for the health of conservation staff [22]. Variations in sodium hydroxide baths and electrochemical reduction treatments are among the most common treatments [23]. The former is the process of removal of chlorides through osmotic diffusion, while the latter utilises an electric current to reduce corrosion products back into their metallic state $[24,25]$. One of the latest innovative chemical methods in iron conservation being explored is the application of subcritical fluids [24]. The subcritical fluid methodology used by the Warren Lasch Conservation Center immersed objects in a flowing alkaline solution at $100{ }^{\circ} \mathrm{C}$ and 30 bar pressure. The results of the initial campaign illustrated an effective method for dechlorination. While each method achieves levels of success, issues can arise from the practicality of the setup for large objects, duration of treatment, and the determination of a treatment's termination threshold [22]. Due to the presence of reactive compounds, such as ferric chloride and ferrous sulphate, objects can undergo accelerated corrosion upon dehydration.

The drying process risks the formation of cracks, a collapse of corrosion products formed during burial, the production of voluminous corrosion products, and pitting via acidification [26]. Ferric chloride can convert to brown solid akaganeite upon exposure to the air. Ferrous sulphate causes corrosion above $60 \%$ RH [27]. A brief overview of documented 'safe' parameters for archaeological ironworks suggests that being below $11 \%$ or at a minimum below $20 \%$ is required depending on chloride content and the stability of the corrosion products formed [28-30].

Biologically based treatments provide a potentially greener alternative to remove damaging corrosion and create biogenic mineral passivation layers. There are a variety of documented microorganisms with iron cycling and bioconversion capabilities [31]. Additionally, the utilisation of salts for the growth of many bacteria is well known [32]. 
These two capabilities provide the basis for designing biologically driven iron treatmentsdesalination, biocleaning, and biopassivation via biomineralisation.

The premise of the biomineral formation and biocleaning of iron revolves around selected microorganisms' natural iron cycling mechanisms. In the absence of oxygen, some organisms use $\mathrm{Fe}^{3+}$ as a terminal electron acceptor for respiration and reduce insoluble $\mathrm{Fe}^{3+}$ oxides via extracellular electron transport [33]. This reduction process can be achieved via cytochromes located in the external membrane of the cell, cellular appendages (pili/nanowires) that form a bridge for electron transfer, the use of siderophores ( $\mathrm{Fe}^{3+}$ chelators), or electron shuttles [34,35].

The concept of biomineralisation and iron reduction has long been researched by a number of industry sectors for a multitude of applications, such as waste remediation, biomining, biosynthesis, and sedimentary geological studies [36]. Desalination has primarily been researched in the industrial and wastewater sector. A number of cyanobacteria (photosynthetic and oxygen-producing bacteria) and Geobacter spp. have been utilised for desalination in the wastewater sector as bioelectroactive bacteria, which cause the separation of salts via ionic exchange [37-40]. At the same time, the conservation sector has begun to explore microbial applications for biocleaning and bioconversion of iron [41,42]. Research conducted on Alternaria sp. indicated its potential application as a biocleaner due to its siderophore production [43]. Recently, Aeromonas sp. and Shewanella spp. have been assessed for the bioreduction of iron species and production of a passivation layer [43-48]. Aeromonas spp. successfully produced a partially biomineralised surface on exposed coupons and archaeological nails. However, neither completely converted the reactive surface, and there were risks that the unidentified Aeromonas spp. could be pathogenic. Shewanella sp. illustrated an ability to produce partial vivianite and siderite layers on archaeological iron $[46,49]$. Shewanella loihica and Shewanella oneidensis demonstrated notable potential for biocleaning via bioreduction $[47,48,50]$. Additionally, Pseudomonas putida was studied for the production of a phosphated-iron protective coating and the production of a biofilm on mild steel [51-54].

This biomineralisation concept is one that bio-based treatments have already begun to explore for the preservation of cultural heritage. However, increased consideration is needed to optimise their development for the specific conservation of iron artefacts. This manuscript assessed the bioremediation of salt contaminates and a passivation layer by specific bacteria (Figure 1). Prioritisation for testing was given to those bacteria required close to neutral $\mathrm{pH}$, near room temperature, no salt amendment, and aerotolerant growth. Additionally, microorganisms were eliminated if potentially hazardous or presenting unknown risks [55]. 


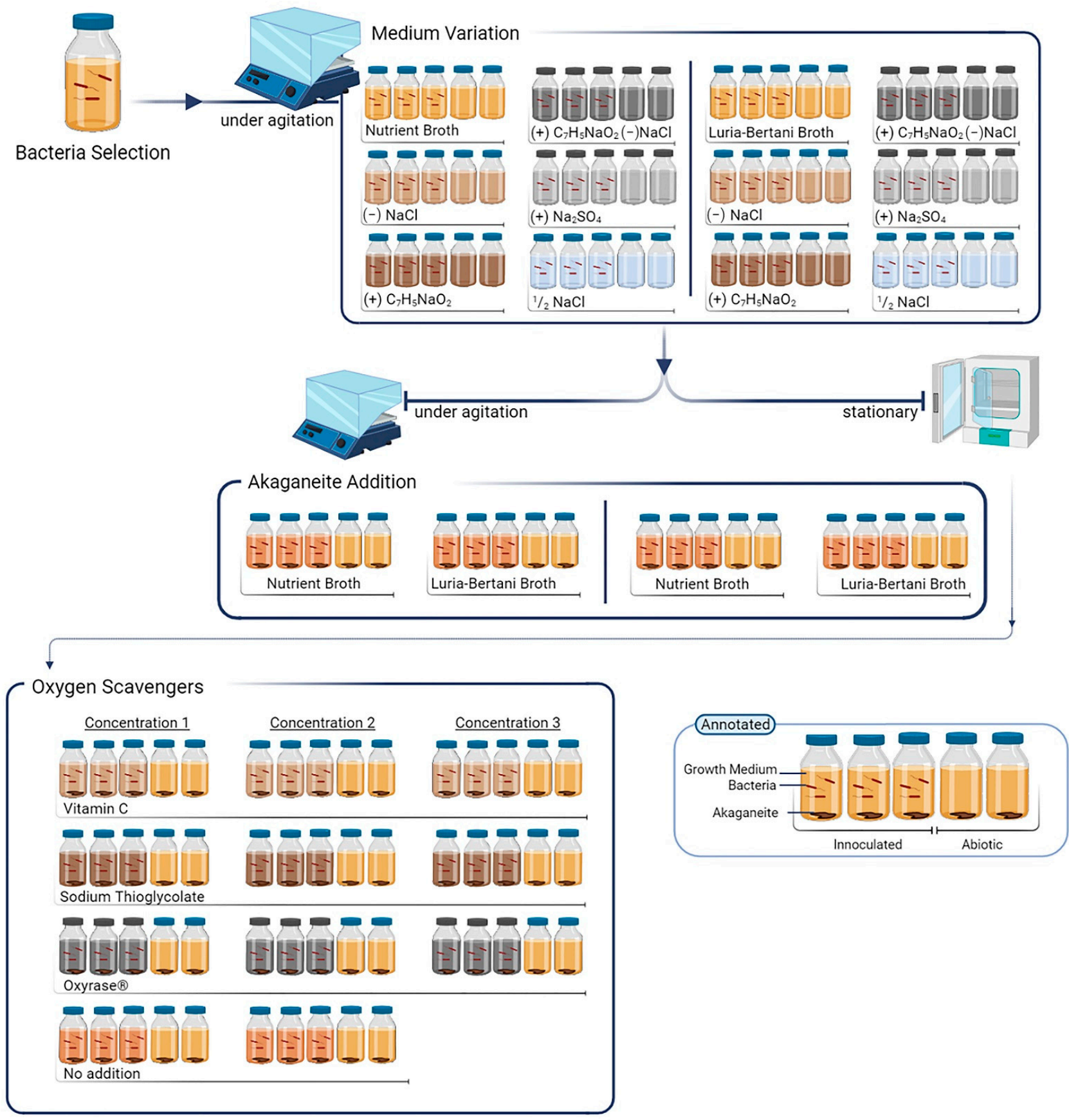

Figure 1. Illustration of manuscript workflow with visual representation of sample replication following biological standard for triplicates and controls, created using the BioRender.com illustration platform.

\section{Materials and Methods}

\subsection{Bacterial Cultivation}

For each experiment, the cultivation of Pseudomonas putida $\mathrm{mt} 2$ prior to inoculation was performed aerobically using either a Nutrient Broth medium (NB; $1.5 \%(w / v)$ Peptone (soytone), $0.5 \%(w / v)$ yeast extract, $1 \%(w / v)$ sodium chloride $\mathrm{NaCl}, 1 \mathrm{~g} / \mathrm{L} \mathrm{DL} \pm$ Glucose) or Luria-Bertani medium (LB; $1 \%(w / v)$ tryptone, $0.5 \%(w / v)$ yeast extract, and $1 \%(w / v)$ sodium chloride $\mathrm{NaCl}$ ) at $25-30{ }^{\circ} \mathrm{C}$ under agitation at $130 \mathrm{rpm}$. After aerobic cultivation overnight, the bacterial biomass was collected via centrifugation (5000 rpm for $15 \mathrm{~min}$ at $9{ }^{\circ} \mathrm{C}$ ) and washed three times with either LBS or NBS matrix-variants without an additional salt/sodium source (Table 1) to prevent carryover of spent medium or salt 
interference in the assessment. Centrifugation was performed with the same settings between each washing step, and the supernatant was discarded each time. The final pellet was resuspended in the same volume of LBS or NBS medium as the overnight and inoculation cultures. Each inoculated bottle consisted of $1 \%(v / v)$ bacterial slurry to a solution with a final volume of $50 \mathrm{~mL}$. All experiments were conducted according to biological standards of triplicates with two controls.

\subsection{Iron Source}

As the selected bacteria have been assessed for use primarily on mild steel, akaganeite was selected for initial experimentation to determine if the response between the bacteria and the high-risk corrosion product achieved similar results [14]. Akaganeite was synthesised following the method outlined by Schwertmann and Cornell [56]. A ratio of $0.99 \mathrm{~g}$ of akaganeite powder (approximately $10 \mathrm{mM}$ Fe content) per $\mathrm{L}$ of culture was employed and sterilised prior to treatment. Sterilisation was twofold: the addition of a few drops of 3:1 ethanol/acetone solution onto akaganeite powder and dried under ultraviolet (UV) light in the laminar flow.

\subsection{Salt Influence on Bacterial Growth}

The elimination of salt in the growth matrix, particularly sodium chloride, was an early goal for future application in actual praxis. The exclusion of additional $\mathrm{NaCl}$ prevents possible introduction or exacerbation of chloride contamination and maintains the desalination goal of archaeological and historical iron stabilisation. Several media were prepared with different amounts and types of sodium sources to ascertain the influence that sodium and anions have on bacterial growth and to assess the salt requirements for optimal bacterial growth. Six variations were made on two primary media, Nutrient Broth (NB) and Luria-Bertani Medium (LB) (Table 1). Sodium chloride was selected as the traditional sodium source employed in microbial cultures. Sodium sulphate was chosen as an alternate sodium salt to determine the role chlorides have on microbial growth compared to sodium. Sodium benzoate was selected based on inclusion in Volkand medium recipes for phosphating iron protocols [57]. All solutions started with near-neutral $\mathrm{pH}$. Turbidity was measured using the SpectraMax i3x multi-mode plate reader (Thermo Fisher Scientific, Waltham, MA, USA) for growth rate assessment based on light absorbance (optical density) over a $48 \mathrm{~h}$ period.

\subsection{Agitation Effect on Biomineralisation}

Traditional broth-based growth is performed under agitation to ensure nutrient availability. However, no agitation is preferred for scalability purposes. Agitation would limit any treatment protocol's applicability and prevent the alteration of treatment from solutionbased to gels in the future. Gel application would provide continuous contact between the object and the bacterial treatment without the need for large volumes of solution or materials. Additionally, gels have an initial oxygen-limiting potential which could aid the biomineral reduction process. Thus, screening was performed to determine the effect agitation has on the bioconversion of iron phases.

Sets of LB and NB variations without salt addition, LBS and NBS, respectively, were placed under agitation and a static environment with akaganeite powder as an iron source. Inoculated bottles were placed at $28-30{ }^{\circ} \mathrm{C}$ in either an oven or an oscillating incubator set to $130 \mathrm{rpm}$. Solution samples were taken weekly throughout the experiment to monitor $\mathrm{pH}$, chlorides, and iron content within the solution. The composition of iron species present was assessed before and after treatment using X-ray diffraction (XRD) for the phases' analysis and scanning electron microscopy coupled with energy-dispersive X-ray spectroscopy (SEM-EDS) for the elemental identification. Samples of the solid phases for this assessment were collected after two weeks and at the end of the experiment after 12 weeks. 
Table 1. LB and NB broth variation.

\begin{tabular}{|c|c|c|c|c|c|c|c|c|c|c|c|c|c|c|c|}
\hline \multicolumn{8}{|c|}{ NB Variations } & \multicolumn{8}{|c|}{ LB Variations } \\
\hline Label & Soytone (g/L) & Yeast (g/L) & Glucose (g/L) & & Sodium & Sourc & $(g / L)$ & Label & Soytone (g/L) & Yeast $(\mathrm{g} / \mathrm{L})$ & Glucose (g/L) & & Sodium & Sourc & $(g / L)$ \\
\hline NBa (NB) & 15 & 5 & 1 & 10 & $\mathrm{NaCl}$ & - & - & LBa (LB) & 10 & 5 & - & 10 & $\mathrm{NaCl}$ & - & - \\
\hline NBb (NBS) & 15 & 5 & 1 & - & - & - & - & LBa (LBS) & 10 & 5 & - & - & - & - & - \\
\hline $\mathrm{NBc}$ & 15 & 5 & 1 & 10 & $\mathrm{NaCl}$ & 0.865 & $\begin{array}{l}\text { Sodium } \\
\text { Benzoate }\end{array}$ & $\mathrm{LBC}$ & 10 & 5 & - & 10 & $\mathrm{NaCl}$ & 0.865 & $\begin{array}{l}\text { Sodium } \\
\text { Benzoate }\end{array}$ \\
\hline NBd & 15 & 5 & 1 & - & - & 0.865 & $\begin{array}{l}\text { Sodium } \\
\text { Benzoate }\end{array}$ & LBd & 10 & 5 & - & - & - & 0.865 & $\begin{array}{l}\text { Sodium } \\
\text { Benzoate }\end{array}$ \\
\hline NBe & 15 & 5 & 1 & 10 & $\mathrm{Na}_{2} \mathrm{SO}_{4}$ & - & - & LBe & 10 & 5 & - & 10 & $\mathrm{Na}_{2} \mathrm{SO}_{4}$ & - & - \\
\hline NBf & 15 & 5 & 1 & 5 & $\mathrm{NaCl}$ & - & - & LBf & 10 & 5 & - & 5 & $\mathrm{NaCl}$ & - & - \\
\hline
\end{tabular}




\subsection{Application of Oxygen Scavengers on Biomineralisation}

A large number of microorganisms that produce biominerals do so either as strict anaerobes or under low oxygen-induced stress. Therefore, various oxygen scavengers were selected to counteract the impracticality of maintaining a purely anoxic environment and assess the impact on mineralisation.

Several oxygen scavengers were selected for assessment at three different concentrations based on literature recommendations and technical data sheets (Table 2): Vitamin C (VIT), Sodium Thioglycolate (THIO), and an enzymatic solution named Oxyrase ${ }^{\circledR}$ (OXR). Inoculated bottles containing NBS medium amended with the three different oxygen scavengers and akaganeite powder were placed at $28-30{ }^{\circ} \mathrm{C}$ in an oven without further agitation.

Table 2. Oxygen scavenger variations.

\begin{tabular}{ccccc}
\hline \multirow{2}{*}{ Solution } & & \multicolumn{3}{c}{ Concentration } \\
\cline { 3 - 5 } & & $\mathbf{1}$ & $\mathbf{2}$ & $\mathbf{3}$ \\
\hline Vitamin C (Vit) & $\mathrm{mg} / \mathrm{L}$ & 100 & 250 & 500 \\
\hline Sodium Thioglycolate (Thio) & $\mathrm{mg} / \mathrm{L}$ & 250 & 500 & 1000 \\
\hline Oxyrase for Broth (OXR) & $\mathrm{mL} / \mathrm{L}$ & 0.625 & 1.250 & 1.875 \\
\hline No Addition (Norm) & - & & \\
\hline
\end{tabular}

Two control sets without an oxygen scavenger (NORM) were used [58-61]. Vitamin C, also known as ascorbic acid, was selected as a cost-effective oxygen scavenger; however, it also can be utilised as a mild chelator and buffer under different conditions [62]. Sodium thioglycolate was selected for comparison. It is a common reducing agent and oxygen inhibitor in low oxygen biological experimentation; however, concerns about scalability exist due to the chemical's acute toxicity risk [63].

Samples of solid phases for this assessment were only collected at the end of the 12-week experiment to ensure that a decrease in the amount of solid phases present was not due to the disturbance of taking samples throughout the experiment and would not become a confounding variable.

\subsection{Characterisation and Assessment}

Photographs were taken at the start and end of each assessment period to monitor the growth of bacteria and any changes in the visual appearance of culture medium and solid phases.

\subsubsection{SpectraMax i3x Multi-Mode}

Absorbance was measured at $600 \mathrm{~nm}$ using a SpectraMax i3x multi-mode microplate reader in kinetic mode over $48 \mathrm{~h}$. Measurements were taken every hour; the linear shaker function on low was used for agitation for $15 \mathrm{~min}$ each hour.

\subsubsection{Vis Spectrophotometer (VSP)}

Solutions were measured before and after treatment for dissolved iron (LCK320/321) and chlorides (LCK311) using a HACH DR3900 Laboratory VIS spectrophotometer $(\mathrm{HACH}$, Loveland, CO, USA).

\subsection{3. $\mathrm{pH}$ Test}

$\mathrm{pH}$ paper (Fisher Scientific) was used to provide an indication of the $\mathrm{pH}$ by sampling small volumes of culture medium $(100-250 \mu \mathrm{L})$. The volume sampled was selected to maintain the overall volume of initially inoculated solutions. 


\subsubsection{Drying and Preparation Protocol}

Upon completing the experiment, the incubated solutions were centrifuged at $5000 \mathrm{rpm}$ for $30 \mathrm{~min}$ at $9^{\circ} \mathrm{C}$. The supernatant was collected for ICP-OES testing, while the solid pellets were sterilised and dried using stepwise $25 \%, 50 \%, 75 \%$, and $90 \%(v / v)$ ethanol solution in water and then, pure ethanol and acetone [48]. Samples were then slightly ground using a mortar and pestle before their SEM-EDS and XRD analysis.

\subsubsection{Inductive Coupled Plasma-Optical Emission Spectroscopy (ICP-OES)}

The supernatants were sterilised using a $0.22 \mu \mathrm{m}$ PVDF Syringe Filter before being analysed for iron and sulphur content using a Optima 2100 ICP-OES (Perkin-Elmer, Waltham, MA, USA).

2.6.6. Scanning Electron Microscopy Coupled with Energy Dispersive X-Ray Spectroscopy (SEM-EDS)

Dried samples were mounted on stubs using carbon conductive tape. Before analysis, the stubs were stored in desiccators with silica gel to avoid humidification. A Thermo Fisher Scientific FIB (focused ion beam) Scios 2 DualBeam scanning electron microscope (Thermo Fisher Scientific, Waltham, MA, USA) with an energy-dispersive X-ray analyser was used. The samples were observed using an EDS detector, an acceleration potential of 2-15 kV, and a 7-10 mm working distance.

\subsubsection{X-ray Diffraction (XRD)}

Dried samples were measured on a zero-background sample holder using a Malvern Panalytical X'Pert Pro MPD (Multi-purpose diffractometer) powder diffractometer (Almelo, The Netherlands) equipped with the $\mathrm{Cu}$ K anode (=1.5405 $\AA$ ) and Goebel mirror in the primary optics. The diffractograms were collected under reflection mode at a range of $5-100^{\circ}$ in $2 \theta$ with a time per step of $2 \mathrm{~s}$, and step size of 0.05 . For obtaining useful statistical data, an accumulative mode of 40 scans was used. X'pert HighScore Plus software (version 2.2e/2.2.5), with a multiple reference database (CSD and ICSD database), was used to identify crystalline phases.

\section{Results and Discussion}

\subsection{Salt Parameters}

Pseudomonas putida $\mathrm{mt} 2$ is known to grow with small amounts of sodium chloride in solution. Variations in LB and NB solutions were tested to determine the necessity of salt in the growth of the bacteria prior to bioconversion assessments (Table 1).

Absorbance results illustrated that Pseudomonas was capable of growing with and without the presence of salt in various forms without notable variations in group rates. SpectraMax measurements, shown in Figure 2, indicate an increased rate of growth and plateau in O.D. of NB variations over LB variations. Average NB variations reached an absorbance of $1.19 \pm 0.21$ O.D. at $22.17 \pm 10.44 \mathrm{~h}$, while LB variations average an absorbance factor of $0.92 \pm 0.09$ O.D. at $32.17 \pm 8.16 \mathrm{~h}$. NB variations had an increased growth rate, reaching a plateau with higher O.D. in a shorter timeframe. In terms of maximum absorbance within each set, average standard deviations of 0.017 overall, 0.024 between LB sets and 0.010 for NB variations were observed.

Additionally, the average standard error overall is 0.010 . Each variation has minimal effect on the overall growth of the bacteria. A slight preference was seen in chloride- and sulphate-based salts in NB variations and no salt and sodium benzoate in LB variations.

Moreover, the medium's base iron and chloride levels were determined with Vis Spectrophotometry measurements (VSP). Chlorides were monitored to assess the level of chlorides introduced to an artefact during treatment and to determine any potential effect on the bacteria's growth rate. Iron levels were observed to ascertain the degree of dissolution of the akaganeite during abiotic and biotic treatments. LB broths contain tryptone $(10 \mathrm{~g} / \mathrm{L})$, and NB broths contain peptone $(15 \mathrm{~g} / \mathrm{L})$ and soytone for our experiments. As 
such, tryptone-based media were found to contain more chlorides than soytone variations as chlorides readings were within the range of one another despite the increased quantity of soytone compared to LB tryptone (Table 3).

\section{A}
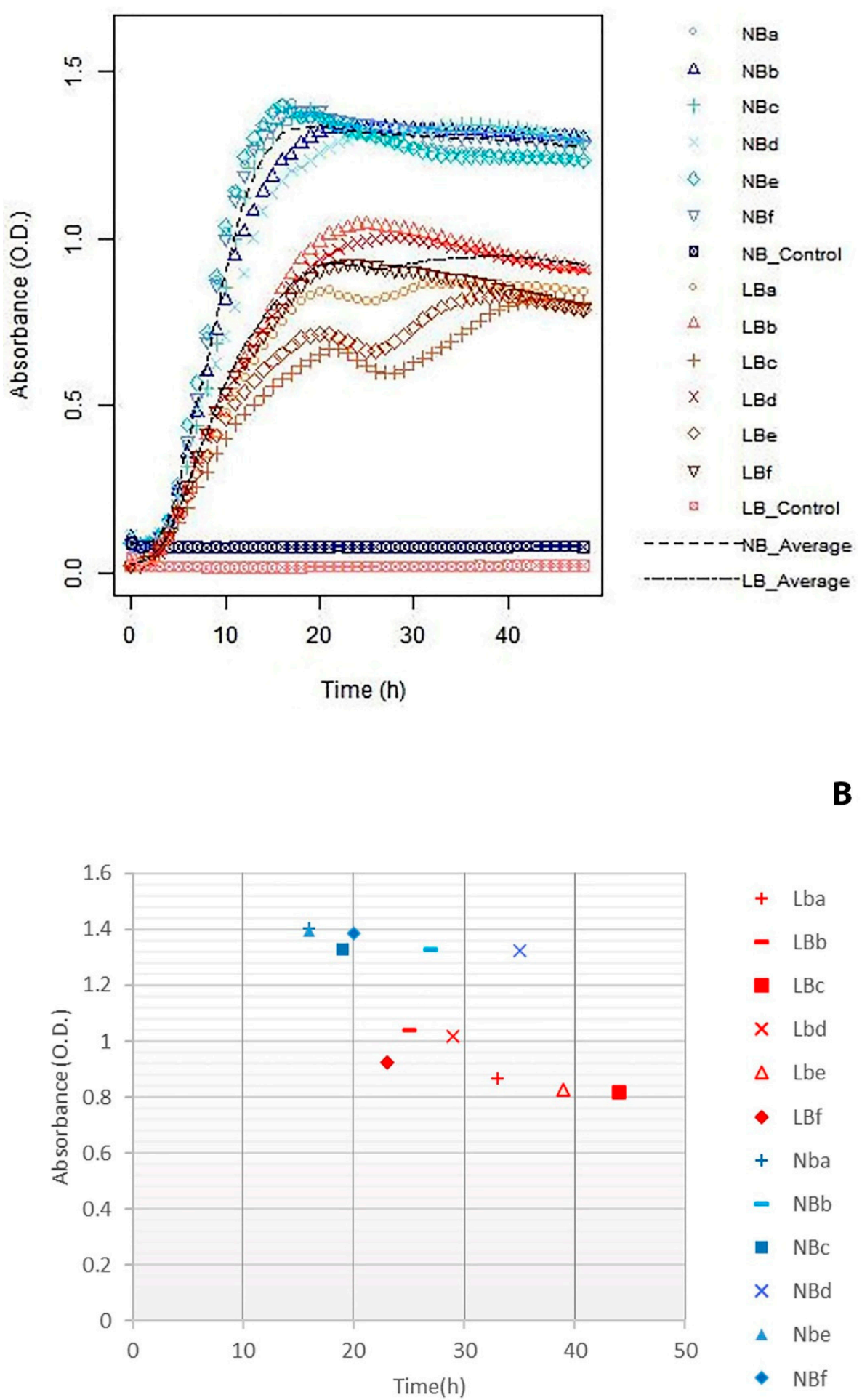

+ Lba

- LBb

- LBC

$\times$ Lbd

$\Delta$ Lbe

- LBf

$+\mathrm{Nba}$

- NBb

- $\mathrm{NBC}$

$\times$ NBd

- Nbe

- NBf

Figure 2. Illustration of the effect salt variation has on the growth rate of Pseudomonas putida mt2 with averages of both sets of LB (blue symbols) and NB (red symbols) variations. (A) Average absorbance curve collected using SpectraMax. (B) Average maximum values of each medium variation at a given time. 
Table 3. Base values of iron and chloride content between traditional and the no salt variations of LB and NB and LBS and NBS, respectively, using Colour Vis Spectrophotometry (VSP) and Inductive Coupled Plasma-Optical Emission Spectroscopy (ICP).

\begin{tabular}{cccc}
\hline \multirow{2}{*}{ Solution } & \multicolumn{2}{c}{ Iron Content $(\mathrm{mg} / \mathrm{L})$} & Chloride Content $(\mathrm{mg} / \mathrm{L})$ \\
\cline { 2 - 4 } & VSP & ICP & VSP \\
\hline LBa (LB) & $1.01 \pm 0.24$ & 1.02 & $6403.33 \pm 125.03$ \\
\hline LBb (LBS) & $1.31 \pm 0.34$ & 2.06 & $153.67 \pm 1.15$ \\
\hline NBa (NB) & $1.48 \pm 0.02$ & 1.03 & $6176.67 \pm 51.32$ \\
\hline NBb (NBS) & $2.85 \pm 0.13$ & - & $52.30 \pm 10.4$ \\
\hline
\end{tabular}

Testing verified the potential for growth without additional salt, and colour spectrophotometry verified that chloride content in NB variations with soytone is initially lower than LB variations with tryptone. In conservation, the aim is stabilisation through the removal of chlorides or other harmful anions. As growth was not inhibited with the exclusion of salt from the standard solutions, chloride limitation in the initial solution was prioritised in further experimentation.

NBS (NB variation without salt) grew at an increased absorbance of the salt-free variations, despite having a lower initial chloride content. This result indicates the potentially more considerable positive impact of glucose over chloride content on the growth rate. Secondarily, ICP testing illustrated that LBS (LB variation without salt) had a higher initial iron level than LB before adding akaganeite powder $(2.06$ and $1.02 \mathrm{mg} / \mathrm{L}$, respectively). $\mathrm{NB}$ had an initial iron level of $1.03 \mathrm{mg} / \mathrm{L}$ in the stock solution. Colour spectrophotometry base iron levels in LBS and LB before akaganeite addition measured $1.31 \pm 0.34$ and $1.01 \pm 0.24 \mathrm{mg} / \mathrm{L}$, respectively, as indicated in Table 3. This variation between ICP and VSP readings in stock LBS solution is partially mitigated by the variation within the composition of medium components, such as yeast which is not standardised, and the standard deviation of the VSP samples. As ICP is an elemental analysis, it is considered more accurate in this instance, and future assessment needs to be performed to determine potential interference in VSP chemical reaction.

\subsection{Agitation Versus Static}

Initial SEM-EDS and XRD results indicate that partial conversion has occurred in both agitated and non-agitation samples of both media. Additionally, according to SEMEDS observations, chloride levels within the mineral appear to have diminished in all samples. Chlorine measurements indicated an initial range of $19.3-24.0 \%$ and a final range of $1.9-5.5 \%$. The percentage of phosphorous increased from non-quantifiable trace amounts to approximately $30 \%$ in some samples. Agitated samples reached approximately $18-30 \%$ phosphorous, while non-agitated samples increased only between 5 and 10\%.

Additionally, trace calcium, potassium, magnesium, manganese, sulphur, aluminium, and silicon were found without notable pattern between LBS and NBS samples both under and without agitation. This suggests the initial conversion of the akaganeite mineral and, consequently, the potential decrease in chloride content in the mineral, further supported by XRD analyses (Figure 3). Mineral digestion is necessary to determine accurate chloride content; SEM-EDS merely indicates elemental content. 


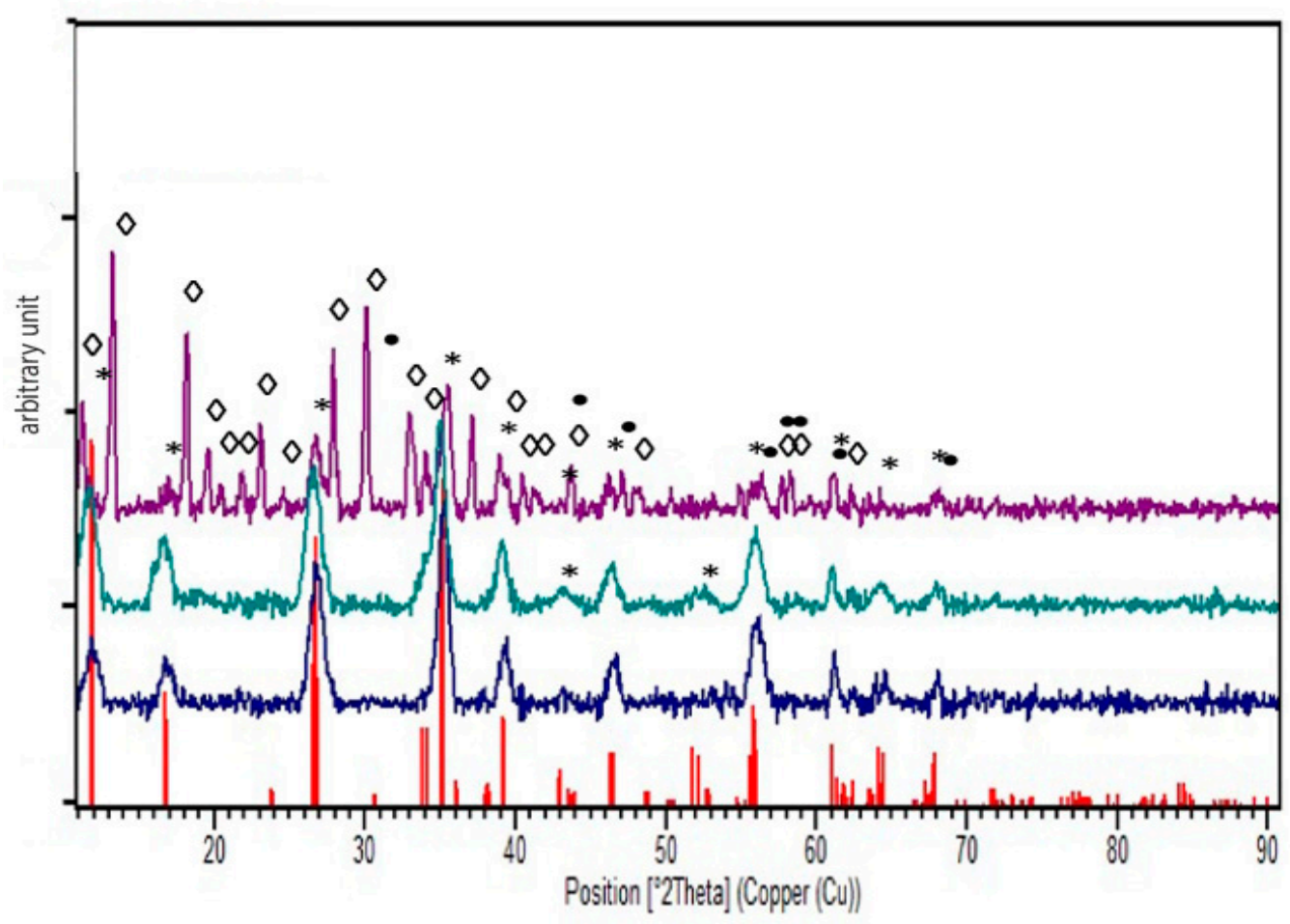

Figure 3. XRD diffractograms of NBS cultures media measured under agitation (purple, top), stationary (teal, middle), and abiotic control (navy, bottom) and compared to the akaganeite reflections from the ISCD database indicated in red. Akaganeite is indicated with $\left[{ }^{*}\right]$, vivianite is indicated with $[\diamond]$, and Iron Sulphide is indicated with $[\bullet]$.

The XRD diffractogram patterns denote incomplete and irregular mineral transformation between samples from initial akaganeite towards other iron compounds. Under agitation, the akaganeite in the NBS medium was significantly transformed into vivianite and iron sulphide. In comparison, the non-agitated medium showed less pronounced iron sulphide and akaganeite contents. The presence of iron sulphides is consistent with expectations due to the composition of the nutrient media utilised and purported to result from microbial intervention. Similarly, ICP results indicated a higher quantity of sulphur in abiotic controls with respect to bacterial sets (data not shown). The LBS agitated samples showed the presence of maghemite and magnetite, where the LBS non-agitated samples contained traces of iron phosphate and oxide hydroxide (data not shown). Reference codes for these patterns can be found in Supplementary Table S1. Agitated samples appeared more efficient in the conversion process; however, agitation may not be feasible for all future applications in real praxis. Additionally, the success of agitation on powder samples does not provide a complete comparison with actual artefacts, given the increased surface area and distribution of mineral into solution under agitation. Agitation and stationary protocols require further exploration, but prioritisation is being given to stationary applications for versatility purposes.

The increase in chloride content in solutions via VSP further suggested the dissolution of the chloride-containing mineral structure into solution. The mineral structure remained primarily akaganeite; however, the decrease in chloride content in mineral phases illustrated desalination treatment potential. ICP results after treatment indicated iron levels increased to $68.55 \mathrm{mg} / \mathrm{L}$ in bacterial cultures and of $103.56 \mathrm{mg} / \mathrm{L}$ in abiotic controls in LBS non-agitated samples, whereas NBS non-agitated samples averaged $57.87 \mathrm{mg} / \mathrm{L}$ of iron with increased variability and $8.66 \mathrm{mg} / \mathrm{L}$ in abiotic controls. The large increase in iron in the solution for both inoculated NBS and LBS media at the end of the experiment illustrated the dissolution potential of akaganeite. Both LBS and NBS illustrated disassociation of the akaganeite and thus, are potentials for biocleaning. LBS non-agitated abiotic controls 
suggested a significantly higher dissolution potential of the mineral compared to NBS non-agitated abiotic samples. However, the higher volumes of solubilised iron in abiotic LBS solutions over inoculated samples indicate an iron precipitation effect of bacterial solutions, supported by XRD and SEM results. Iron content in the non-agitated NBS solutions illustrates bacterial-induced mineral dissociation, suggesting greater potential biocleaning applications. This dissociation was presumed to be partially the result of siderophores production by the bacteria and was confirmed with a CAS (Chrome azurol S) Assay Agar plate (Figure 4).

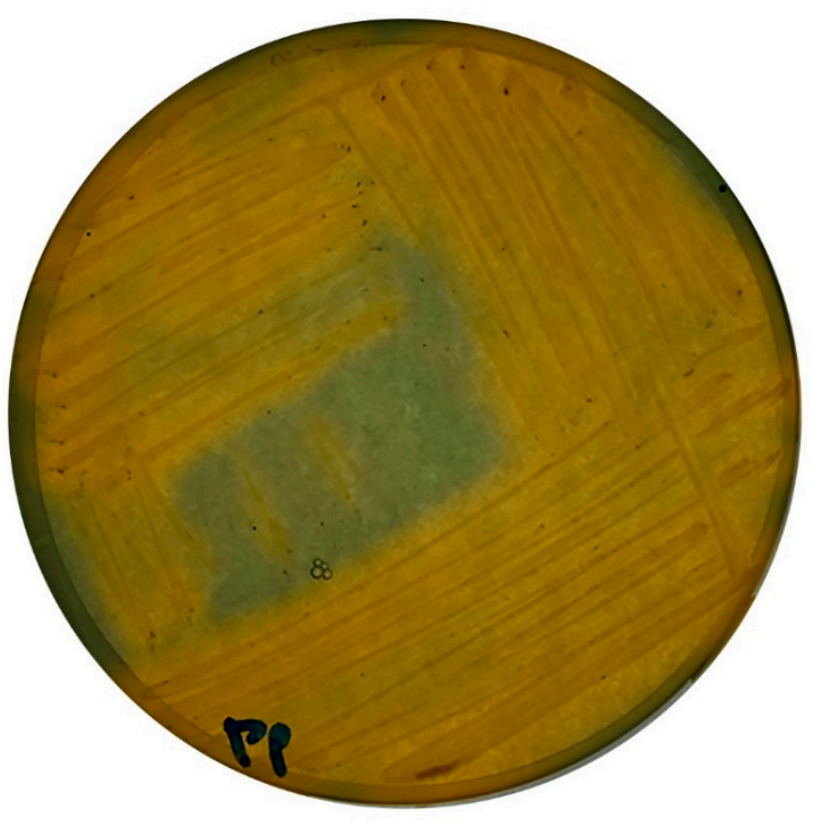

Figure 4. CAS Agar Plate with Pseudomonas putida $\mathrm{mt} 2$ illustrating the production of Siderophores (orange colouration of siderophores complexes).

\subsection{Oxygen Scavengers}

Initial results indicated shifts in visible colour between the abiotic control akaganeite and biotic precipitates. The colour shift is an indication of mineral transformation. The initial colour change occurred quicker than in samples without oxygen scavengers, suggesting the successful impact oxygen scavengers have on the biomineralisation process and perhaps the potential shortening of treatment duration in the future (Figure 5). Similar to previous experimentation, XRD confirmed the presence of akaganeite at the end of the experiment, while SEM-EDS denoted an illustrated drop in chlorine content from 19-24\% to $1-3 \%$. Additionally, SEM-EDS indicated increased potassium levels from nearly $0 \%$ in the akaganeite standard to approximately $9 \%$; however, due to the percent error, these results cannot be fully substantiated with this method. For instance, $0.42 \%$ of $\mathrm{K}$ with an $8.30 \%$ error were identified in the akaganeite standard. Fluctuating sulphur levels, phosphorous, and trace amounts of calcium, silicon, and sodium were identified. Some EDS spectra indicated potential trace amounts of magnesium, manganese, and other metals (i.e., titanium, copper, zinc) of values outside the range of error to verify. The unusual elemental composition in selected areas is partially the result of residual organic materials that survived the sterilisation and washing protocol performed before SEM-EDS analyses. Chlorine measurements decreased in SEM-EDS from initial akaganeite readings of 19-24\% to $1-3 \%$, while spectrophotometry of solutions shows increased chloride levels (Figure 6). Every inoculated solution illustrated an increase in chloride content compared to their respective stock solutions, with the exception of sodium thioglycolate $(1000 \mathrm{mg} / \mathrm{L}$; THIO3). Chlorides measurements after treatment measured consistently with a mean value of $246.5 \mathrm{mg} / \mathrm{L}$. These results further support the success of the treatment to extract chlorides. 


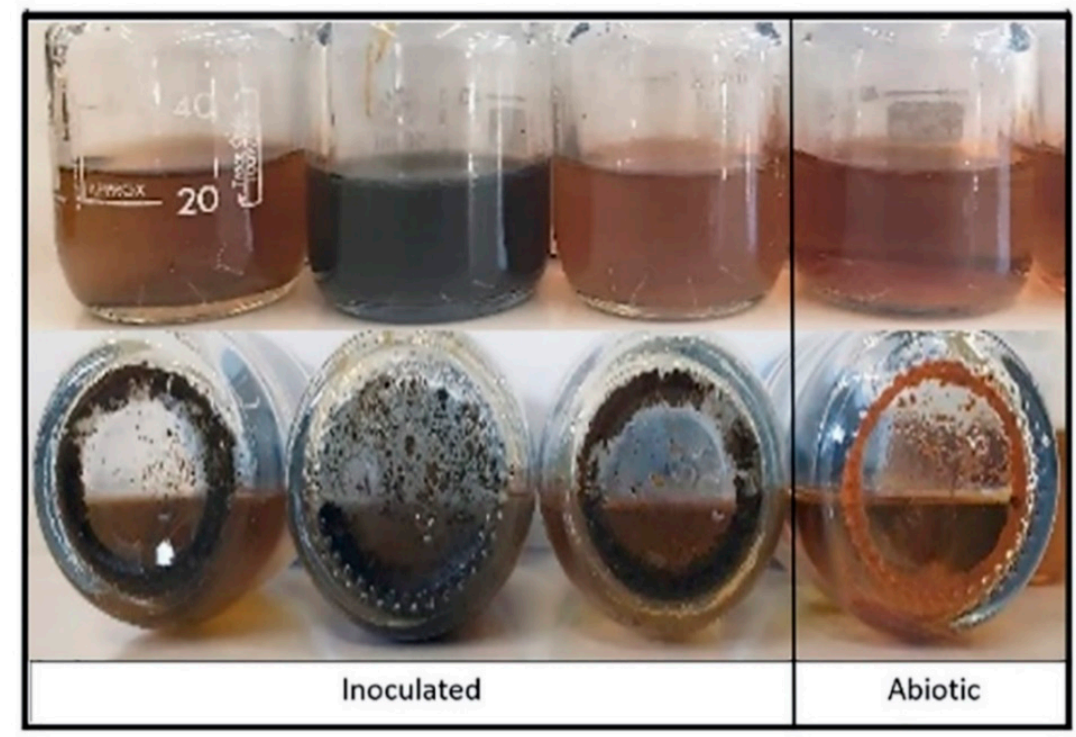

Figure 5. Left: Image of sodium thioglycolate (500 mg/L; THIO2) solutions 3 weeks after inoculation and in abiotic control.

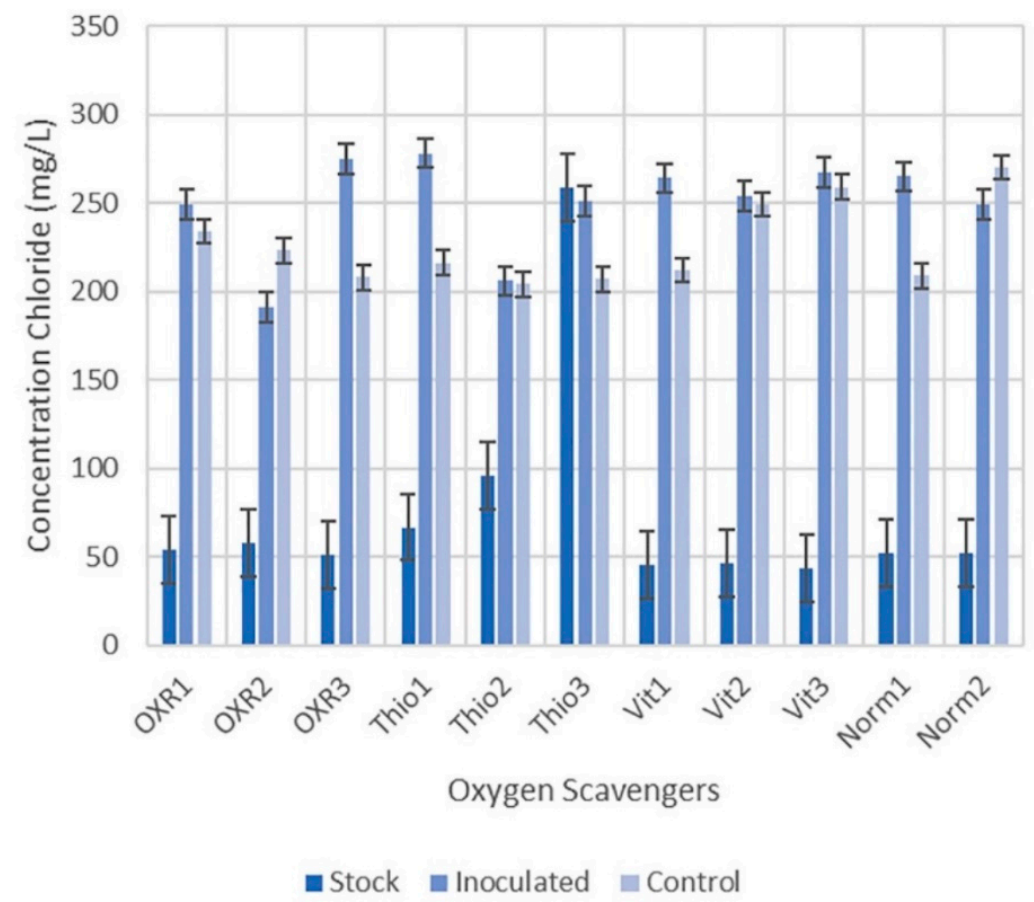

Figure 6. Illustration of chloride content with standard error bars for oxygen scavenger initial (Stock) solutions, and after treatment for inoculated and control samples of Oxyrase ${ }^{\circledR}$ (OXR), Sodium Thioglycolate (THIO), Vitamin C (VIT), and no scavenger added (NORM) at their respective concentrations outlined in Table 2.

The extraction of chlorides coupled with the increased iron indicated the dissolution of the akaganeite into solution. NBS solutions' base iron levels are approximately $2.69 \mathrm{mg} / \mathrm{L}$, according to VSP. Additionally, iron levels for sodium thioglycolate solutions initially contained $1.38 \pm 0.03 \mathrm{mg} / \mathrm{L}$ of iron, and Oxyrase solutions began at $4.08 \pm 0.77$ of iron. Abiotic and biotic samples experienced an increase in iron in the solution throughout the experiment. In LBS and NBS solutions, samples without an oxygen scavenger (NORM2) demonstrated an increase in iron of approximately 2.07 times the original values in both 
biotic and abiotic solutions. In contrast, sodium thioglycolate (1000 mg/L; THIO3) showed an approximate increase in iron of up to 53.04 times the original value. The increase in iron dissolution in solutions utilising oxygen scavengers poses both the potential for biocleaning and the increased risk of damage to cultural heritage artefacts. This concern was mitigated by the understanding that many iron artefacts undergo mechanical removal, and thus the iron loss, by comparison, would be negligible. Additionally, the shift between week one and the final solution, as seen in the figure, denoted a drop in iron concentration by the end of the experiment (Figure 7). This is further supported by the XRD results, which indicated an increased mineral shift.

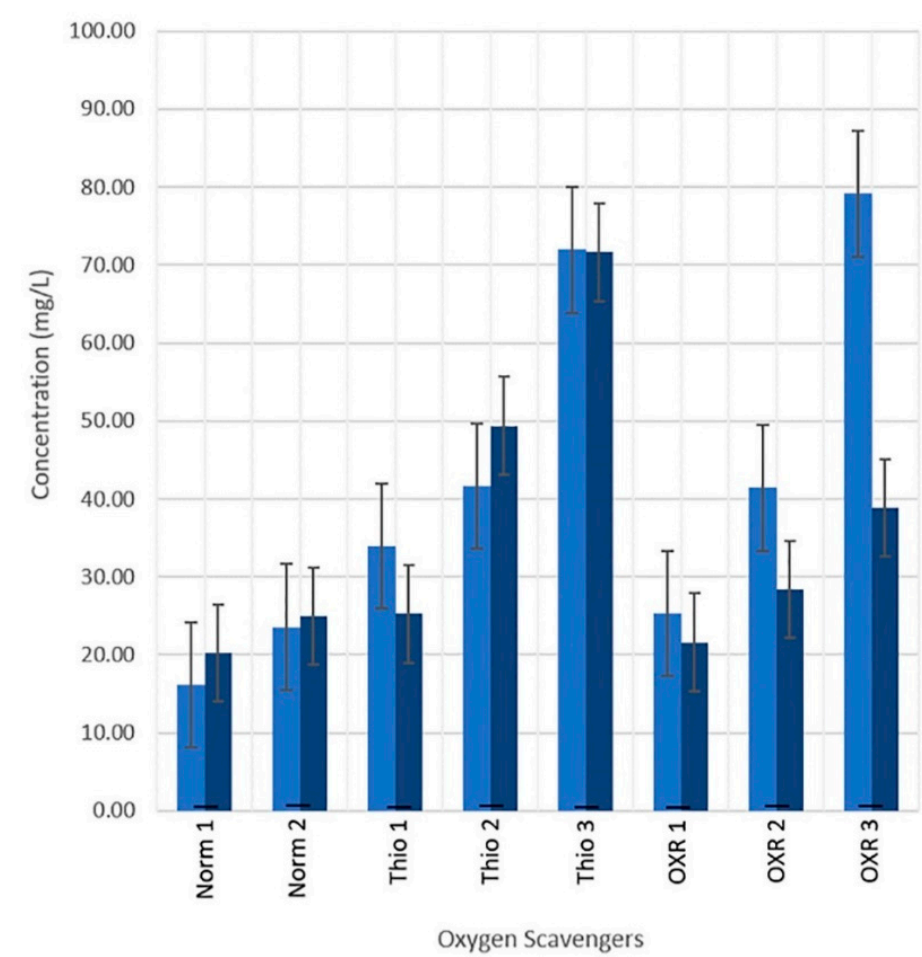

Figure 7. ICP results: iron average content with standard error bars for oxygen scavenger solutions after the first week (W1 averages, left columns) and after treatment (final averages, right columns).

Figure $8 \mathrm{~A}-\mathrm{C}$ illustrate the $\mathrm{XRD}$ diffraction patterns of the various oxygen scavenger groups tested. Similar to results from agitation and non-agitation, akaganeite was still evident, similar to the no addition sample sets of this experiment. However, in contrast to the NORM samples, the oxygen scavenger diffractograms displayed an increased alteration of crystalline phases from akaganeite towards other iron compounds. The variation even amongst samples groups was not ideal. Nevertheless, we believe the results show a direct experimental root for the verification of biomineral conversion and the benefit of an oxygen scavenger in iron disassociation and biomineral reduction. 

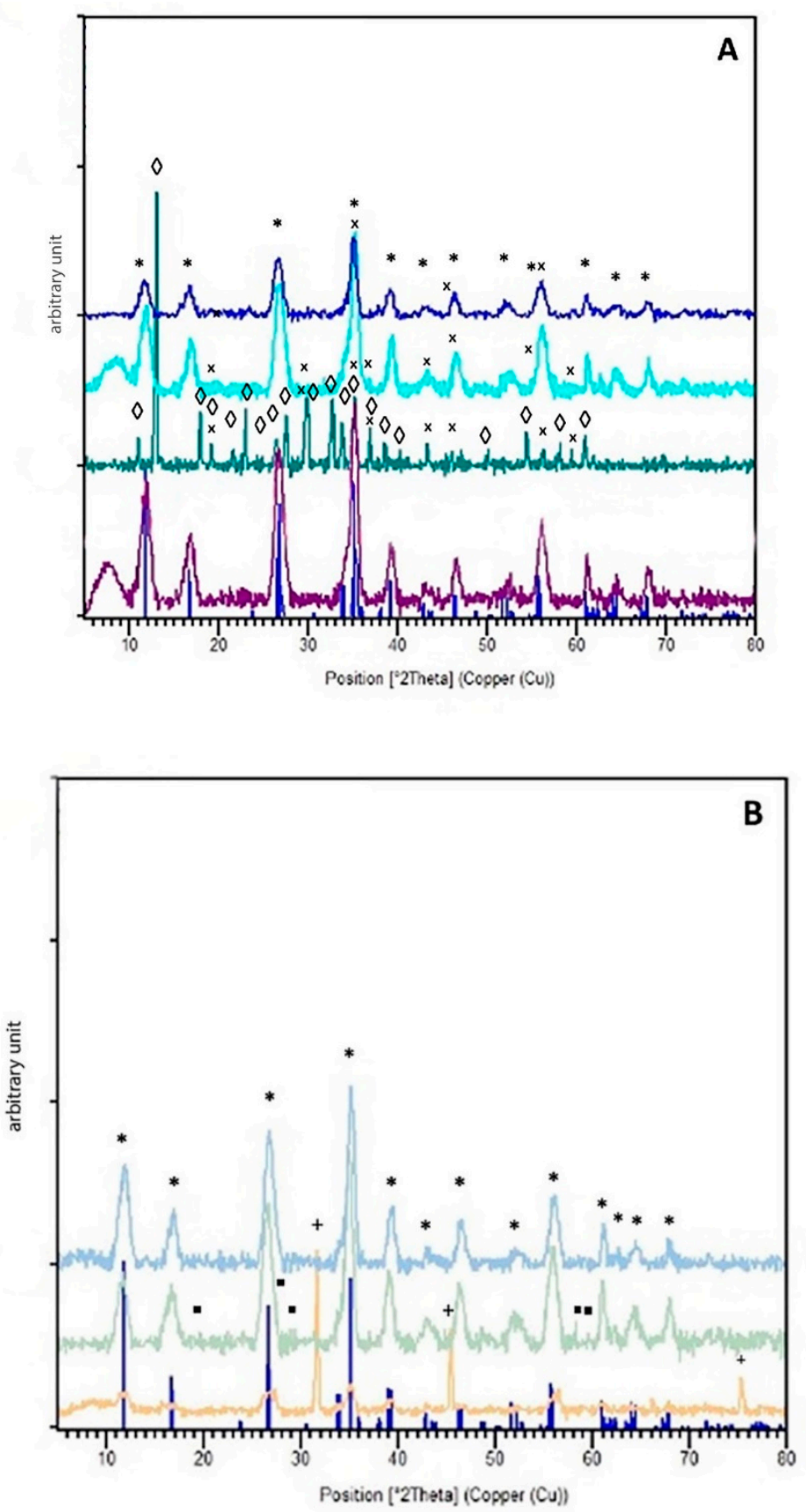

Figure 8. Cont. 


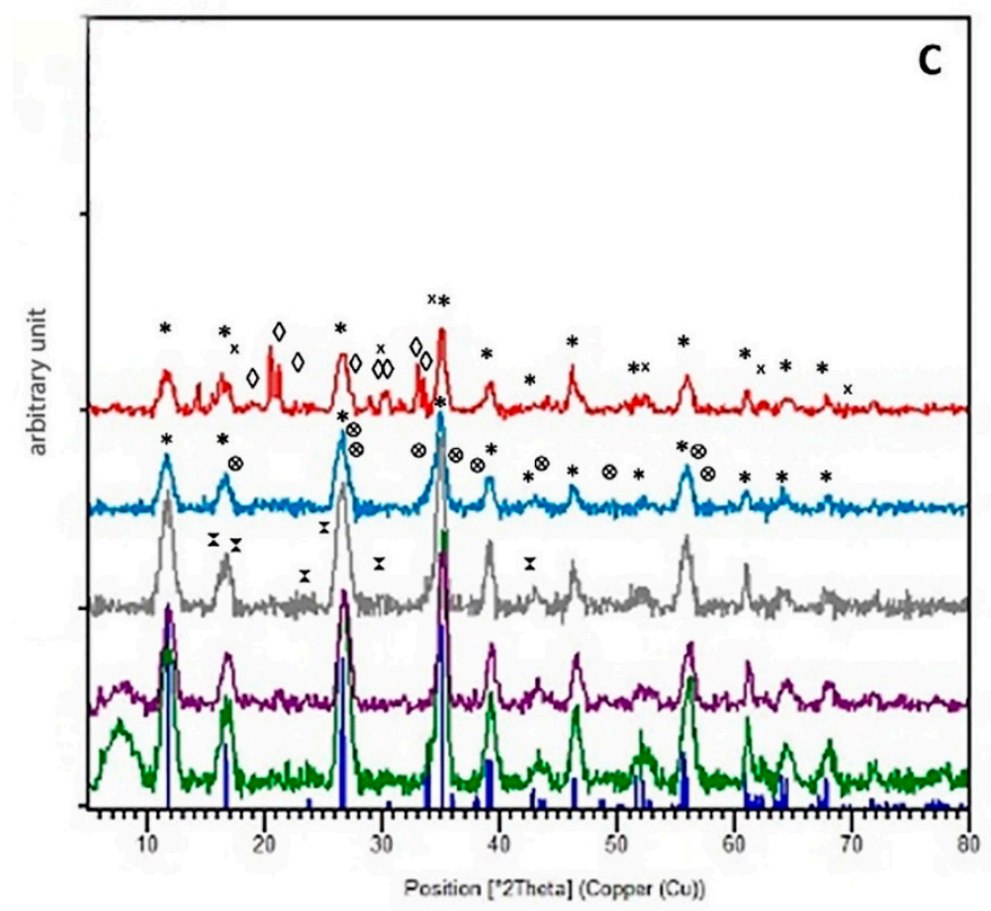

Figure 8. XRD diffractogram results of NBS samples with different oxygen scavengers: Oxyrase (A), No additives (B), and Sodium Thioglycolate (C). The dark blue lines denote the akaganeite reference pattern. (A) XRD patterns for Oxyrase solution from top to bottom: $0.625 \mathrm{~mL} / \mathrm{L}, 1.250 \mathrm{~mL} / \mathrm{L}$, $1.875 \mathrm{~mL} / \mathrm{L}$, and abiotic control at $0.625 \mathrm{~mL} / \mathrm{L}$. (B) From top to bottom: no additives, abiotic control, pre-treatment Akaganeite. (C) XRD patterns for sodium thiosulfate from top to bottom: $250 \mathrm{mg} / \mathrm{L}$, $250 \mathrm{mg} / \mathrm{L}, 500 \mathrm{mg} / \mathrm{L}, 1000 \mathrm{mg} / \mathrm{L}$, abiotic control at $500 \mathrm{mg} / \mathrm{L}$. Peaks associated with specific compound phases are indicated the following symbols: Akaganeite is indicated with [*], vivianite is with

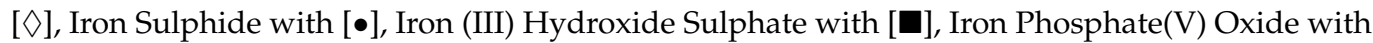

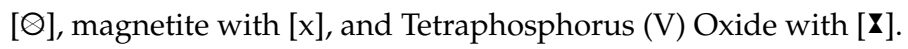

\section{Conclusions}

This research aims to support the development of a greener conservation treatment protocol that would meet the needs and restrictions of practical conservation (i.e., ease of application, health and safety, cost, equipment needs, and the potential need for retreatment in the future). Pseudomonas putida $\mathrm{mt} 2$ can be manipulated for desalination, biocleaning and bioconversion of iron corrosion products from initial testing. It does not require salt or agitation for growth. Agitation is effective in powdered samples but presents limitations for future application. Thus, prioritisation was given to the development of a stationary application and gel application in future assessments on corroded surfaces.

Oxygen scavengers increased conversion; however, products obtained were inconsistent within sample sets. Desalination was evident in the diminished chloride content between inoculated samples. ICP-OES results illustrated the increase in iron content in inoculated solutions, indicating the potential for biocleaning application. However, future testing should further monitor the development of iron sulphides and the reduction of sulphur in culture mediums as microbial sulphur reduction is the primary avenue for sulphur-based iron corrosion [18,19].

Additional assessment is needed to optimise and define potential further application of this bacterial strain. Further research is being conducted on medium manipulation, medium renewal effect, additional oxygen scavenger testing, iron source alteration, secondary bacteria, and bacterial mixtures.

In terms of analysis, IC (Ion Chromatography) will be utilised to confirm spectrophotometry measurements for chlorides. Eventually, optimised bacterial results will be as- 
sessed for long-term stability alongside classic chemical treatment options using various analytical techniques.

Supplementary Materials: The following are available online at https:/ /www.mdpi.com/article/10 $.3390 / \mathrm{cmd} 2020015 / \mathrm{s} 1$, Table S1: XRD mineral identification reference list from the ICSD database.

Author Contributions: Conceptualisation, E.J.; methodology, S.J. and E.J.; software, S.J.; validation, S.J. and E.J.; formal analysis, S.J.; investigation, S.J.; data curation, S.J.; writing-original draft preparation, S.J.; writing — review and editing, S.J. and E.J.; visualisation, S.J.; supervision, E.J.; project administration, E.J.; funding acquisition, E.J. All authors have read and agreed to the published version of the manuscript.

Funding: This research was funded by the Swiss National Science Foundation (SNSF); grant number PP00P2_163653/1, MICMAC (MICrobes for Archaeological Wood Conservation) project 2016-2020.

Institutional Review Board Statement: Not applicable.

Informed Consent Statement: Not applicable.

Data Availability Statement: The data presented in this study are available on request from the corresponding author. The data are not publicly available yet as the establishment of acceptable open access repository is in progress.

Acknowledgments: The authors would like to thank NPAC (Neuchatel) for running ICP analysis Perkin-Elmer Optima 2100 ICP-OES, CSEM (Neuchatel) for access to the XRD and SEM-EDS systems, Laboratory of Microbiology (Neuchatel, UniNE) for access to the UVM microplate reader, and Laboratory of Evolutionary Genetics for access to the SpectraMax i3x multi-mode plate reader.

Conflicts of Interest: The authors declare no conflict of interest.

\section{References}

1. Bottrill, M.C.; Pressey, R.L. The effectiveness and evaluation of conservation planning. Conserv. Lett. 2012, 5, 407-420. [CrossRef]

2. Dietze-Uldry, S.; (Service Archéologique du Canton de Bern, Suisse); Küpfer, L.; (Laboratoire MCAH, Lausanne, Switzerland). Personal communication, 2020.

3. Réguer, S.; Neff, D.; Remazeilles, C.; Guilminot, E.; Nicot, F.; Pelé, C.; Meguelati, M.; Mirambet, F.; Dillmann, P.; Refait, P.; et al. Desalinisation of iron archaeological artefacts: Understanding of chlorine removal mechanisms of the corrosion layers with the help of characterisation techniques. In Metal 07: Interim Meeting of the ICOM-CC Metal WG Amsterdam, 17-21 September 2007; Rijksmuseum: Amsterdam, The Netherlands, 2007; pp. 60-68.

4. Gerwin, W.; Baumhauer, R. Effect of soil parameters on the corrosion of archaeological metal finds. Geoderma 2000, 96, 63-80. [CrossRef]

5. Ståhl, K.; Nielsen, K.; Jiang, J.; Lebech, B.; Hanson, J.C.; Norby, P.; van Lanschot, J. On the akaganéite crystal structure, phase transformations and possible role in post-excavational corrosion of iron artifacts. Corros. Sci. 2003, 45, 2563-2575. [CrossRef]

6. Keller, P. Eigenschaften von $(\mathrm{C} 1, \mathrm{~F}, \mathrm{OH})<{ }_{2} \mathrm{Fe}_{8}(\mathrm{O}, \mathrm{OH})_{16}$ und akaganéit. Neues Jahrb. Min. 1970, 113, $29-49$.

7. Reguer, S.; Mirambet, F.; Bellot-Gurlet, L.; Dillmann, P. Local and structural characterisation of chlorinated phases formed on ferrous archaeological artefacts by mu XRD and mu XANES. Nucl. Instrum. Methods Phys. 2005, 240, 500-504. [CrossRef]

8. Watkinson, D. Measuring effectiveness of washing methods for corrosion control of archaeological iron: Problems and challenges. Corros. Eng. 2010, 45, 400-406. [CrossRef]

9. Watkinson, D.E.; Emmerson, N.J. The impact of aqueous washing on the ability of $\beta$ FeOOH to corrode iron. Environ. Sci. Pollut. Res. 2016, 24, 2138-2149. [CrossRef]

10. Bland, P.A.; Kelley, S.P.; Berry, F.J.; Cadogan, J.M.; Pillinger, C.T. Artificial weathering of the ordinary chondrite Allegan; implications for the presence of $\mathrm{Cl}$-as a structural component in akaganeite. Am. Miner. 1997, 82, 1187-1197. [CrossRef]

11. Watkinson, D.; Lewis, M.T. Desiccated storage of chloride-contaminated archaeological iron objects. Stud. Conserv. 2005, 50, 241-252. [CrossRef]

12. Rimmer, M.; Thickett, D.; Watkinson, D.; Ganiaris, H. Guidelines for the Storage and Display of Archaeological Metalwork; English Heritage: Swindon, UK, 2013.

13. Zucci, F.; Morigi, G.; Bertolasi, V. Beta iron oxide hydroxide formation in localized active corrosion of iron artifacts. Corrosion and metal artifacts: A dialogue between conservators and archaeologists. Natl. Bur. Stand. Spec. Publ. 1977, 479, 103-106.

14. Selwyn, L.S.; Sirois, P.J.; Argyropoulos, V. The corrosion of excavated archaeological iron with details on weeping and akaganéite. Stud. Conserv. 1999, 44, 217. [CrossRef]

15. Watkinson, D. Degree of mineralisation: Its significance for the stability and treatment of excavated ironwork. Stud. Conserv. 1983, 28, 85-90. 
16. Thickett, D. Post Excavation Changes and Preventive Conservation of Archaeological Iron. Ph.D. Thesis, University of London, London, UK, 2012. Available online: https://production.english-heritage.org.uk/siteassets/home/learn/conservation/ collections-advice--guidance/thickettthesisfinalversion.pdf (accessed on 5 June 2020).

17. Logan, J. Care and Cleaning of Iron; CCI Notes; Minister of Public Works and Government Services Canada: Quebec, QC, Canada, 2007; pp. 1-4.

18. Walker, R. Instability of iron sulfides on recently excavated artifacts. Stud. Conserv. 2001, 46, 141-152.

19. Rémazeilles, C.; Saheb, M.; Neff, D.; Guilminot, E.; Tran, K.; Bourdoiseau, J.-A.; Sabot, R.; Jeannin, M.; Matthiesen, H.; Dillmann, P.; et al. Microbiologically influenced corrosion of archaeological artefacts: Characterisation of iron (II) sulfides by Raman spectroscopy. J. Raman Spectrosc. 2010, 41, 1425-1433. [CrossRef]

20. Neff, D.; Reguer, S.; Bellot-Gurlet, L.; Dillmann, P.; Beranger, G. Corrosion of iron archaeological artefacts in soil: Characteri-sation of the corrosion system. Corros. Sci. 2005, 47, 515-535. [CrossRef]

21. Rimmer, M.; Watkinson, D.; Wang, Q. The impact of chloride desalination on the corrosion rate of archaeological iron. Stud. Conserv. 2013, 58, 326-337. [CrossRef]

22. Rimmer, M. Investigating the Treatment of Chloride-Infested Archaeological Iron Objects. Ph.D. Thesis, Cardiff University, Cardiff, UK, 2010.

23. Rimmer, M.; Wang, Q. Assessing the effects of alkaline desalination treatments for archaeological iron using Scanning electron microscopy. Br. Mus. Tech. Res. Bull. 2010, 4, 79-86.

24. Näsänen, L.M.; González-Pereyra, N.G.; Cretté, S.A.; DeViviés, P. The applicability of subcritical fluids to the conservation of actively corroding iron artifacts of cultural significance. J. Supercrit. Fluids 2013, 79, 289-298. [CrossRef]

25. Zou, X.; Gu, S.; Lu, X.; Xie, X.; Lu, C.; Zhou, Z.; Ding, W. Electroreduction of iron (III) oxide pellets to iron in alkaline media: A typical shrinking-core reaction process. Met. Mater. Trans. A 2015, 46, 1262-1274. [CrossRef]

26. Watkinson, D.E.; Rimmer, M.B.; Emmerson, N.J. The influence of relative humidity and intrinsic chloride on post-excavation corrosion rates of archaeological wrought iron. Stud. Conserv. 2019, 64, 456-471. [CrossRef]

27. Evans, U.; Taylor, C. Mechanism of atmospheric rusting. Corros. Sci. 1972, 12, 227-246. [CrossRef]

28. Crowyn, J. The Elements of Archaeological Conservation; Routledge: Eastbourne, UK, 1990.

29. Thickett, D.; Odlyha, M. The formation and transformation of akaganeite. In Proceedings of the Interim Meeting of the International Council of Museums Committee for Conservation Metal Working Group, Edinburgh, Scotland, 16-20 September 2013; pp. 103-109.

30. Oudbashi, O.; Shekofteh, A.; Makhzani, S.; Siapoosh, M. Conservation of metal collection in Ebn-E Sina Museum, Hamedan, Iran: From intervening to preventive approaches. In Proceedings of the YOCOCU 2014: Professionals' Experiences in Cultural Heritage Conservation in America, Europe, and Asia: Proceedings of International Conference, Youth in the Conservation of Cultural Heritage, Agsu, Azerbaijan, 28-30 May 2014.

31. Su, C.; Zhang, M.; Lin, L.; Yu, G.; Zhong, H.; Chong, Y. Reduction of iron oxides and microbial community composition in iron-rich soils with different organic carbon as electron donors. Int. Biodeterior. Biodegrad. 2020, 148, 104881. [CrossRef]

32. Atlas, R. Handbook of Microbiological Media, 4th ed.; CRC Press: Boca Raton, FL, USA, 2010.

33. Esther, J.; Sukla, L.B.; Pradhan, N.; Panda, S. Fe (III) reduction strategies of dissimilatory iron reducing bacteria. Korean J. Chem. Eng. 2015, 32, 1-14. [CrossRef]

34. Brutinel, E.D.; Gralnick, J.A. Shuttling happens: Soluble flavin mediators of extracellular electron transfer in Shewanella. Appl. Microbiol. Biotechnol. 2011, 93, 41-48. [CrossRef]

35. Zachara, D.; Kukkadapu, R.; Fredrickson, J.; Gorby, Y.; Smith, S. Biomineralisation of a poorly crystalline Fe (III) oxide, ak-aganeite, by an anaerobic Fe (III)-reducing bacterium (Shewanella alga) isolated from marine environment. Geomicrobiol. J. $2003,7,217$.

36. Konhauser, K. Diversity of bacterial iron mineralization. Earth-Sci. Rev. 1998, 43, 91-121. [CrossRef]

37. Amezaga, J.M.; Amtmann, A.; Biggs, C.A.; Bond, T.; Gandy, C.J.; Honsbein, A.; Karunakaran, E.; Lawton, L.; Madsen, M.A.; Minas, K.; et al. Biodesalination: A case study for applications of photosynthetic bacteria in water treatment. Plant Physiol. 2014, 164, 1661-1676. [CrossRef]

38. Cao, X.; Huang, X.; Liang, P.; Xiao, K.; Zhou, Y.; Zhang, X.; Logan, B.E. A new method for water desalination using microbial desalination cells. Environ. Sci. Technol. 2009, 43, 7148-7152. [CrossRef]

39. Ramírez-Moreno, M.; Rodenas, P.; Aliaguilla, M.; Bosch-Jimenez, P.; Borràs, E.; Zamora, P.; Monsalvo, V.; Rogalla, F.; Ortiz, J.M.; Esteve-Núñez, A. Comparative performance of microbial desalination cells using air diffusion and liquid cathode reactions: Study of the salt removal and desalination efficiency. Front. Energy Res. 2019, 7, 1-12. [CrossRef]

40. Pedireddy, S.; Jimenez-Sandoval, R.; Ravva, M.K.; Nayak, C.; Anjum, D.H.; Jha, S.N.; Katuri, K.P.; Saikaly, P.E. Harnessing the extracellular electron transfer capability of Geobacter sulfurreducens for ambient synthesis of stable bifunctional single-atom electrocatalyst for water splitting. Adv. Funct. Mater. 2021, 2010916. [CrossRef]

41. Preston, J.; Smith, A.D.; Schofield, E.J.; Chadwick, A.; Jones, M.A.; Watts, J.E.M. The effects of Mary Rose conservation treatment on iron oxidation processes and microbial communities contributing to acid production in marine archaeological timbers. PLoS ONE 2014, 9, e84169. [CrossRef]

42. Comensoli, L.; Kooli, W.; Monachon, M.; Albini, M.; Junier, P.; Joseph, E. The potential of microorganisms for the conserva-tionrestoration of iron artworks. In Proceedings of the Metal 2019 Interim Meeting of the ICOM-CC Metals Working Group; Chemello, C., 
Brambilla, L., Joseph, E., Eds.; International Council of Museums Committee for Conservation (ICOM-CC) and Haute Ecole Arc Conservation-Restauration (HE-Arc CR): Neuchatel, Switzerland, 2019; pp. 242-249. ISBN 978-92-9012-458-0.

43. Comensoli, L. Interaction between Microbes, Iron and Chlorine for the Development of Biotechnological Approaches to Stabilise Corroded Iron. Ph.D. Thesis, University of Neuchatel, Neuchatel, Switzerland, 2017.

44. Comensoli, L.; Albini, M.; Kooli, W.; Maillard, J.; Lombardo, T.; Junier, P.; Joseph, E. Investigation of biogenic passivating layers on corroded iron. Materials 2020, 13, 1176. [CrossRef] [PubMed]

45. Kooli, W.M.; Comensoli, L.; Maillard, J.; Albini, M.; Gelb, A.; Junier, P.; Joseph, E. Bacterial iron reduction and biogenic mineral formation for the stabilisation of corroded iron objects. Sci. Rep. 2018, 8, 1-11. [CrossRef] [PubMed]

46. Kooli, W.M.; Junier, T.; Shakya, M.; Monachon, M.; Davenport, K.W.; Vaideeswaran, K.; Vernudachi, A.; Marozau, I.; Monrouzeau, T.; Gleasner, C.D.; et al. Remedial treatment of corroded iron objects by environmental Aeromonas isolates. Appl. Environ. Microbiol. 2018, 85, e02042-18. [CrossRef]

47. Benaiges-Fernandez, R.; Palau, J.; Offeddu, F.G.; Cama, J.; Urmeneta, J.; Soler, J.M.; Dold, B. Dissimilatory bioreduction of iron (III) oxides by Shewanella loihica under marine sediment conditions. Mar. Environ. Res. 2019, 151, 104782. [CrossRef]

48. Kooli, W. Bacterial Iron Reduction and Biogenic Mineral Formation for the Stabilisation of Corroded Iron Objects. Ph.D. Thesis, University of Neuchatel, Neuchatel, Switzerland, 2018.

49. Comensoli, L.; Maillard, J.; Albini, M.; Sandoz, F.; Junier, P.; Joseph, E. Use of bacteria to stabilize archaeological iron. Appl. Environ. Microbiol. 2017, 83. [CrossRef]

50. Roh, Y.; Gao, V.H.; Vali, H.; Kennedy, D.W.; Yang, Z.K.; Gao, W.; Dohnalkova, A.C.; Stapleton, R.D.; Moon, J.-W.; Phelps, T.J.; et al. Metal reduction and iron biomineralization by a psychrotolerant Fe(III)-reducing bacterium, Shewanella sp. strain PV-4. Appl. Environ. Microbiol. 2006, 3236-3244. [CrossRef]

51. Volkland, H.; Harms, H.; Wanner, O.; Zehnder, A. Corrosion protection by anaerobiosis. Water Sci. Technol. 2001, 44, 103-106. [CrossRef]

52. Joseph, E.; James, S.; Albelda-Berenguer, M.; Albini, M.; Comensoli, L.; Cornet, E.; Beuret, E.; Kooli, W.; Brambilla, L.; Mathys, L.; et al. Groundbreaking approaches to green and sustainable metals conservation. In ICOM-CC 19th Triennial Conference 2021 Beijing Preprints; International Council of Museums: Paris, France, 2020.

53. Suma, M.; Basheer, R.; Sreelekshmy, B.; Vipinlal, V.; Sha, M.A.; Jineesh, P.; Krishnan, A.; Archana, S.; Saji, V.S.; Shibli, S. Pseudomonas putida RSS biopassivation of mild steel for long term corrosion inhibition. Int. Biodeterior. Biodegrad. 2019, 137, 59-67. [CrossRef]

54. Suma, M.S.; Basheer, R.; Sreelekshmy, B.R.; Riyas, A.H.; Bhagya, T.C.; Sha, M.A.; Shibli, S.M.A. Synergistic action of Bacillus subtilis, Escherichia coli and Shewanella putrefaciens along with Pseudomonas putida on inhibiting mild steel against oxygen corrosion. Appl. Microbiol. Biotechnol. 2019, 103, 5891-5905. [CrossRef] [PubMed]

55. Frey, J. Part 1: Bacteria in Classification of Organisms; Institut für Veterinärbakteriologie, University Bern: Bern, Switzerland, 2010.

56. Schwertmann, U.; Cornell, R. The Iron Oxides in the Laboratory: Preparation and Characterization, 2nd ed.; Wiley-VCH: Weinheim, Germany, 2000.

57. Volkland, H.-P.; Harms, H.; Müller, B.; Repphun, G.; Wanner, O.; Zehnder, A.J.B. Bacterial phosphating of mild (unalloyed) steel. Appl. Environ. Microbiol. 2000, 66, 4389-4395. [CrossRef]

58. Jia, Z.; Liu, Y.; Hwang, C.-A.; Huang, L. Effect of combination of Oxyrase and sodium thioglycolate on growth of Clostridium perfringens from spores under aerobic incubation. Food Microbiol. 2020, 89, 103413. [CrossRef] [PubMed]

59. Souza, R.; Peruch, G.; Pires, A.C.D.S. Oxygen scavengers: An approach on food preservation. In Structure and Function of Food Engineering; IntechOpen: London, UK, 2012.

60. Patel, J.R.; Hwang, C.-A.; Beuchat, L.R.; Doyle, M.P.; Brackett, R.E. Comparison of oxygen scavengers for their ability to enhance resuscitation of heat-injured Listeria monocytogenes. J. Food Prot. 1995, 58, 244-250. [CrossRef] [PubMed]

61. Niroomand, F.; Fung, D.Y. Effect of oxyrase on growth of Salmonella spp. and Listeria monocytogenes in the "universal preenrichment medium". J. Rapid Methods Autom. Microbiol. 1992, 1, 241-247. [CrossRef]

62. Liu, S.; Ellars, C.; Edwards, D. Ascorbic acid: Useful as a buffer agent and radiolytic stabilizer for metalloradiopharmaceu-ticals. Bioconj. Chem. 2003, 14, 1052-10526. [CrossRef] [PubMed]

63. National Toxicology Program, U.S. Department of Health and Human Services. Testing Status of Sodium Thioglycolate 10613-K. Available online: https://ntp.niehs.nih.gov/whatwestudy/testpgm/status/ts-10613-k.html?utm_source=direct\&utm_medium= prod\&utm_campaign=ntpgolinks\&utm_term=ts-10613-k (accessed on 4 August 2020). 